\title{
Nanofiber Yapılı Aşırı Yükseltgenmiş Polipirol Modifiye Kalem Ucu Elektrotların Elektrokimyasal Epinefrin Tayininde Kullanımı
}

\author{
Levent Özcan ${ }^{1 *}$ \\ ${ }^{1}$ Afyon Kocatepe Üniversitesi, Mühendislik Fakültesi, Biyomedikal Mühendisliği Bölümü, Afyonkarahisar, Türkiye (ORCID: 0000-0003-4504-4237)
}

(Illk Geliş Tarihi 5 Mart 2019 ve Kabul Tarihi 30 Mayıs 2019)

(DOI: 10.31590/ejosat.535650)

\begin{abstract}
ATIF/REFERENCE: Özcan, L. (2019). Nanofiber Yapılı Aşırı Yükseltgenmiş Polipirol Modifiye Kalem Ucu Elektrotların
\end{abstract} Elektrokimyasal Epinefrin Tayininde Kullanımı. Avrupa Bilim ve Teknoloji Dergisi, (16), 355-362.

Öz

Bu çalışmada, kalem ucu elektrot yüzeyinde elektrokimyasal sentezlenerek aşırı yükseltgenen polipirol nanofiber elektrotlar hazırlanmış ve (KUE/AYPP-NF) epinefrin tayinlerinde elektrokimyasal sensör olarak kullanımı araştırılmıştır. Modifiye elektrodun epinefrin (adrenalin) tayinlerine yönelik elektrokimyasal incelenmesinde ve analitik performanslarının belirlenmesinde dönüşümlü voltametri ve diferansiyel puls voltametri (DPV) tekniği kullanılmıştır. Epinefrin tayinlerine pH'nın etkisi fosfat tamponu çözeltisinde KUE/AYPPNF kullanılarak incelenmiş ve en yüksek pik akımına pH 4,0 değerinde ulaşıldığı tespit edilmiştir. Nanofiber yapıda olmayan aşırı yükseltgeniş polipirol ile karşılaştırıldığında nanofiber yapının epinefrin yükseltgenmesini arttırdığı belirlenmiştir. DPV tekniği kullanılarak KUE/AYPP-NF için epinefrin yükseltgenmesine ait pik akımı 10-200 $\mu \mathrm{M}$ arasında 0,998 korelasyon katsayısı ile doğrusallık göstermektedir. Tayin sınırı (LOD) 2,2 $\mu$ M olarak hesaplanmıştır (S/N=3). Sonuçlar KUE/AYPP-NF elektrotların epinefrin tayinlerinde elektrokimyasal sensör olarak kullanılabileceğini göstermiştir.

Anahtar Kelimeler: Epinefrin, Adrenalin, Nanofiber yapılı polipirol, Aşırı yükseltgenmiş polipirol, Modifiye elektrot, Kalem ucu elektrot.

\section{Electrochemical Epinephrine Determination by Nanofiber Structured Overoxidized Polypyrrole Modified Pencil Graphite Electrodes}

\begin{abstract}
In this study, the overoxidized polypyrrole nanofiber on pencil graphite electrode (PGE/OPP-NF) surface were prepared and investigated to be used as an electrochemical sensor for determination of epinephrine (adrenaline,). Cyclic voltammetry and differential pulse voltammetry techniques were used for electrochemical investigation and determination of analytic performance for epinephrine detection, respectively. The effect of $\mathrm{pH}$ on epinephrine determination was investigated by using PGE/OPP-NF in phosphate buffer solution and the highest peak current was reached at $\mathrm{pH}$ 4.0. It was determined that the nanofiber structure increased the epinephrine oxidation compared to the non-nanofibre structured overoxidized polypyrrole. The peak current of epinephrine oxidation by PGE/OPPNF determined by using DPV technique is linear with a correlation coefficient of 0.998 in the range of 10-200 $\mu \mathrm{M}$.The detection limit (LOD) of epinephrine is $2.2 \mu \mathrm{M}$. The results showed that PGE/OPP-NF electrodes could be used as electrochemical sensors for epinephrine determination.
\end{abstract}

Keywords: Epinephrine, Adrenaline, Nanofiber structured polypyrrole, Overoxidized polypyrrole, Modified electrode, Pencil graphite electrode.

\section{Giriş}

Polimerler, fiziksel ve kimyasal özellikleri belli gereksinimler için uygun hale getirilebildiğinden sensör tasarımı veya çalışmalarında yaygın olarak kullanılır (Adhikari ve Majumdar, 2004). İletken (veya elektroaktif konjuge) polimerlerin elektronik, manyetik ve optik özellikleri nedeniyle bilimsel ve teknolojik önemleri yüksek olup (Retama ve ark., 2005) elektrokimyasal depolama sistemleri, telekominikasyon, moleküler elektronik ve sensör tasarımı gibi uygulamalarda önemleri giderek de artmaktadır (Ahuja ve ark., 2007).

\footnotetext{
* Sorumlu Yazar: Afyon Kocatepe Üniversitesi, Mühendislik Fakültesi, Biyomedikal Mühendisliği Bölümü, Afyonkarahisar, Türkiye, ORCID: 00000003-4504-, leventozcan@aku.edu.tr
} 
Polipirol (PP), iletken polimerler arasında en yaygın kullanılanlardan biridir. Kimyasal ve mekanik olarak dayanıklı olması, farklı malzemeler üzerinde nötral ortamlarda bile elektrokimyasal olarak kolayca sentezlenebilmesi (Wang ve ark., 2001) ve biyolojik uyumluluğu gibi özellikler pek çok çalı̧̧mada polipirolün tercih nedenidir. Bu özelliklerinden dolayı sensör ve/veya biyosensör üretiminde kullanımı yaygındır. Polipirolün özelliklerinin ve kullanım alanlarının incelendiği çok sayıdaki çalışmada polipirolün redoks aktivitesi, iletkenliği, termal kararlılı̆ı ve mekanik özelliği, iyon-değișim ve ayırma kapasitesi, gazlara, DNA molekülüne ve proteinlere karşı güçlü absorpsiyon özellikleri, katalitik aktivitesi ve korozyondan koruma gibi birçok özelliği incelenmiştir. Bu özelliklerin birçoğu hem sentez koşullarına hem de katkı maddesinin yapısına bağlı olarak değişiklik göstermektedir (Ramanavičius ve ark., 2006).

Polipirolün yapısı ve iletkenliği yükseltgenme basamağına bağlıdır. İndirgenmiş polipirol yalıtkan özelliğe sahiptir. PP zincirinin yükseltgenmesi moleküler yapıyı değiştirir ve polimere iletkenlik kazandırır. Nükleofilik gruplar varlığında PP sübstitüe ürünler oluşur. Hidroksil iyonu gibi kuvvetli nükleofil gruplar, konjuge çift bağın yapısını bozan kinon boşluklarının oluşmasına neden olur. Polimerin bu şekilde tersinmez modifikasyonları aşırı yükseltgenme olarak tanımlanır (Mostany ve Scharifker, 1996). Polipirol pozitif gerilimlerde ve çok bazik ortamlarda aşırı yükseltgenir. Aşırı yükseltgenme, katkılanmanın tersine polipirolün iletkenliğinin azalmasına ve nükleofilik saldırılara elverişli hale getirir (Majidi ve ark., 2006). Aşırı yükseltgenme mekanizması henüz tam olarak aydınlatılamamış olmasına rağmen pirol halkasının $\beta$ karbonları üzerinde polimer zincirinin konjugasyonunu engelleyen karbonil gruplarının oluşumu, X-1şınları fotoelektron spektroskopisi (XPS) çalışmaları ile açıklanmıştır (Fernandez ve ark., 2005). Polipirolün aşırı yükseltgenme reaksiyonu Şekil 1'de verilmiştir.

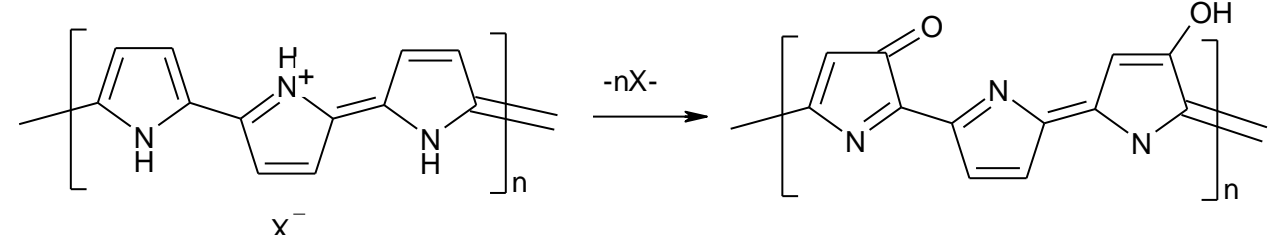

\section{Şekil 1. Polipirolün aşırı yükseltgenme reaksiyonu}

Polimer zincirine karbonil, karboksilat gibi oksijen içeren grupların katılmasıyla katyonik yüklerin azalmasından dolayı aşırı yükseltgenmiş polipirol filmleri, metal iyonları ve ilaçlar gibi katyonik türlere karşı seçicilik gösterir. Büyük çapta anyonların bulunduğu çözeltilerde hazırlanan aşırı yükseltgenmiş polipirol (AYPP), anyonların varlığında katyonik türlerin voltametrik tayini için de kullanılmıştır (Ersöz ve ark., 2002). AYPP, platin elektrot üzerine glikoz oksidaz tutturulmuş bir glikoz biyosensörü çalışmasında kullanılmış ve AYPP'nin anyonik redoks türlerinin girişimini azalttığı görülmüştür (Guerrieri ve ark., 1998). Enzim hapsedilmiş AYPP elektrot, ürenin potansiyometrik tayininde kullanılmış ve kararlı cevaplar elde edilmiştir (Komaba ve ark., 1997). Elektrokimyasal olarak sentezlenen polipirol ve aşırı yükseltgenmiş polipirol elektrotlar, bazı anyon ve katyonların katı-faz ekstraksiyonunda ekstraksiyon kolonu olarak kullanılmıştır. Her iki elektrodun kullanılması ile gerçekleştirilen eşzamanlı elektrokimyasal anyon-katyon ekstraksiyonunda polipirolün anot ve aşırı yükseltgenmiş polipirolün de uygun bir katot olduğu bildirilmiştir (Şahin ve ark. 2008). Bunun yanında biyolojik önemi olan sülfonamitler (Özkorucuklu ve ark., 2011), sistein (Gu ve ark., 2016), dopamin (Koyun ve ark., 2017) ve tetrasiklin (Devkota ve ark., 2018) gibi bileşiklerin elektrokimyasal tayinlerinde başarılı bir şekilde kullanılmıştır.

Şekil 2'de kimyasal yapısı gösterilen ve adrenalin olarak ta bilinen epinefrin [1-(3,4-dihydroxyphenyl)-2-methyloaminoethanol)] kanda taşınan bir hormondur ve nörotransmiter madde olarak işlevi vardır. Kana salgılandığında vücudu acil bir duruma hazırlar (Lawson ve Gorman, 2008). Vücutta epinefrin varlığı kan basıncının düzenlenmesini, kalp hızı, lipoliz, bağışıklık sistemi ve glikojen metabolizmasını etkiler. Parkinson hastalığı olan hastalarda da epinefrin düzeyinin düşük olduğu bulunmuștur (Hsu ve Yang, 2008, Silva ve ark., 2009, Kalimuthu ve Abraham, 2009). Tıbbi uygulamada, acil sağlık durumlarında yaygın olarak kullanılan bir ilaçtır (Selbst ve Cronan, 2000). Epinefrin aynı zamanda anafilaktik şok, bronşiyal astım ve kalp krizi tedavilerinde ilaç olarak kullanılmaktadır (Bergmann ve Goldschmidt, 1968). Bu nedenle vücut sıvılarındaki ve ilaçlardaki epinefrin miktarının hassas ve güvenilir bir şekilde tayin edilmesi önemlidir. Bu kapsamda epinefrin tayinlerinde kullanıma yönelik olarak modifiye elektrot çalışmaları sürdürülmektedir. Bu çalışmalarda modifikasyon aracı olarak grafen (Lavanya ve ark., 2015), karbon kuantum noktaları (Canevari ve ark., 2016), Au-Pd nanokristal (Dong ve ark., 2018), karbon nanotüpler (Ayazi ve ark., 2018) vb. nano boyutlu yapıların tercih edildiği görülmektedir.

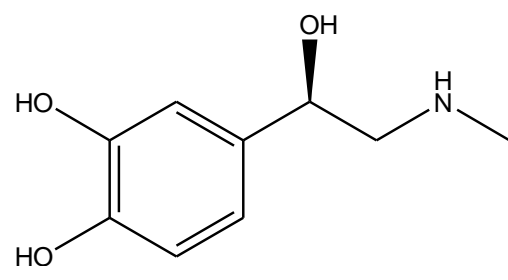

Şekil 2. Epinefrinin kimyasal yapısı

Düşük zemin akımı, kimyasal inertliği, düşük maliyeti, farklı uygulamalar için uygunluğundan dolayı karbon elektrotlar elektroanalitik uygulamalarda kullanılmaktadır. Bunlardan biri olan kalem ucu elektrot (KUE) yüksek elektrokimyasal reaktivitesi, mekanik dayanıklılığı, düşük maliyet ve teknoloji gerektirmesi, modifikasyon, minyatürleştirme ve yenilenmesinin kolaylığı nedeniyle pek çok analitik uygulamada tercih edilmektedir. Diferansiyel puls ve kare dalga voltametrisi gibi oldukça hassas ve yüksek doğrulukta ölçümler yapan voltametrik bir yöntemle birleştiğinde çok çekici bir iz analiz yöntemi karşımıza çıkmaktadır (Gao ve ark., 2005). Kalem ucu elektrodun aktif yüzey alanı fazladır ve düşük derişimlerdeki analitlerin tayinlerinde kullanılabilir. Analit miktarı çok düşük olduğunda bu büyük bir önem kazanmaktadır (Vestergaard ve ark., 2005). Üstelik, camsı karbon gibi ticari karbon kökenli elektrotların 
yeniden kullanılması için tekrar tekrar temizlenmesi ve modifikasyon için pek çok işlemin gerektiği durumlarda, KUE tek kullanımlık olarak kullanılırsa analiz zamanını oldukça kısaltmaktadırlar (Wang ve ark., 2000). Bahsedilen üstünlükleri nedeniyle modifiye edilmiş KUE'nin kafein (Rezaei ve ark., 2014), kapsaisin (Wu ve ark., 2016), dopamin (Özcan ve ark., 2017) ve glukoz (Babu ve ark., 2018) gibi biyolojik önemi olan bileşiklerin tayininde kullanımı yaygınlaşmaya başlamıştır.

$\mathrm{Bu}$ çalışmada elektrokimyasal sentezin kolaylı̆̆ı ve üstünlükleri ile nanofiber yapılı polipirolün avantajları göz önünde bulundurularak KUE yüzeyinde sentezlenmiş nanofiber yapılı aşırı yükseltgenmiş polipirolün epinefrin tayinlerinde kullanımı literatürde ilk defa incelenmiştir.

\section{Materyal ve Metot}

\subsection{Materyal}

\subsubsection{Kimyasal Maddeler ve Elektrotlar}

Epinefrin, perklorik asit, potasyum hidrojen fosfat Sigma-Aldrich (Steinheim, Almanya), potasyum dihidrojen fosfat, sodyum karbonat Merck (Darmstat, Almanya), lityum perklorat Lancaster (Morecambe, İngiltere) firmalarından sağlanmıştır. Pirol Aldrich firmasından temin edilmiş olup renksiz sıvı elde edilinceye kadar vakumda damıtılmış ve kullanılmadığında $-18{ }^{\circ} \mathrm{C}$ 'de saklanmıştır. Kullanılan diğer reaktifler analitik saflıkta olup herhangi bir saflaştırma işlemi yapılmadan doğrudan kullanılmışlardır. Elektrokimyasal çalı̧̧malarda, tampon ve stok çözeltilerin hazırlanmasında kullanılan deiyonize su, TKA marka (Smart2pure model) ultra saf su cihazından elde edilmiştir (direnç: 18,2 M $\Omega$ ).

Çalışma elektrodu olarak kullanılan kurşun kalem uçları (0,7 mm çaplı, 2B, Faber Castell) kırtasiyelerden satın alınmıştır. Kalem uçlarını tutturmak için, uç kısmı metal olan mekanik kalemlerden hazırlanan düzenek kullanılmışıtır. Referans elektrot olarak $\mathrm{Ag} / \mathrm{AgCl}$ (3,0 M KCl), karşıt elektrot olarak 0,25x10x10 mm boyutunda bir Pt levha (Aldrich \% 99,9) kullanılmıştır.

\subsubsection{Cihazlar}

Elektrokimyasal ölçümler CompactStat model (Ivium) potansiyostat-galvanostat cihazı kullanılarak gerçekleştirilmiştir. Bütün elektroanalitik ölçümler oda sıcaklığında yapılmışıır. $\mathrm{pH}$ ölçümlerinde pH-İyon-metre (Thermo), bazı çözeltilerin hazırlanmasında ve elektrotların temizlenmesinde ise ultrasonik banyo (Bandelin Sonorex) kullanılmıştır. Düzenli karıştırma işlemleri isıtıcılı manyetik karıştırıcı (MR3001, IKA) ile gerçekleştirilmiştir.

\subsection{Metot}

\subsubsection{Nanofiber Yapılı Aşırı Yükseltgenmiş Polipirol ile Modifiye Edilmiş Elektrotların Hazırlanması}

Modifiye elektrotlar iki basamakta hazırlanmıştır. Bu basamaklar Şekil 3’te şematik olarak gösterilmektedir. 1) KUE yüzeyinde nanofiber yapılı polipirolün (KUE/PP-NF) elektrokimyasal sentezi. 2) Nanofiber yapılı polipirolün aşırı yükseltgenmesi (KUE/AYPP$\mathrm{NF})$.

KUE/PP-NF elektrotlar $0,10 \mathrm{M} \mathrm{LiClO}_{4}+0,10 \mathrm{M} \mathrm{Na}_{2} \mathrm{CO}_{3}$ ve $0,10 \mathrm{M}$ pirol içeren sulu çözeltide 0,00 ile $0,80 \mathrm{~V}$ arasında $(100 \mathrm{mV} / \mathrm{s})$ 10 döngülü elektropolimerleşme ile hazırlanmıştır. Elde edilen KUE/PP-NF elektrotlar deiyonize su ile yıkanmış ve karbonat iyonlarının karbondioksit olarak uzaklaşabilmesi için \%10'luk $\mathrm{HClO}_{4}$ 'de 24 saat bekletilmiştir (Tian ve ark., 2004).

Hazırlanan KUE/PP-NF'leri aşırı yükseltgemek için $0,15 \mathrm{M} \mathrm{NaOH}$ çözeltisinde $0,00 \mathrm{~V}$ ile $0,90 \mathrm{~V}(100 \mathrm{mV} / \mathrm{s})$ arası 18 döngü ve ardından aynı ortamda ve aynı gerilim aralığında 1 kez DPV ölçümü alınmıştır. Bu işlemler sonucu akım değeri $5 \mu$ A değerine kadar düşmektedir. $\mathrm{Bu}$ aşırı yükseltgeme işlemine tabi tutulan elektrotlar en az 15 dakika deiyonize suda bekletildikten sonra kullanılmıştır.

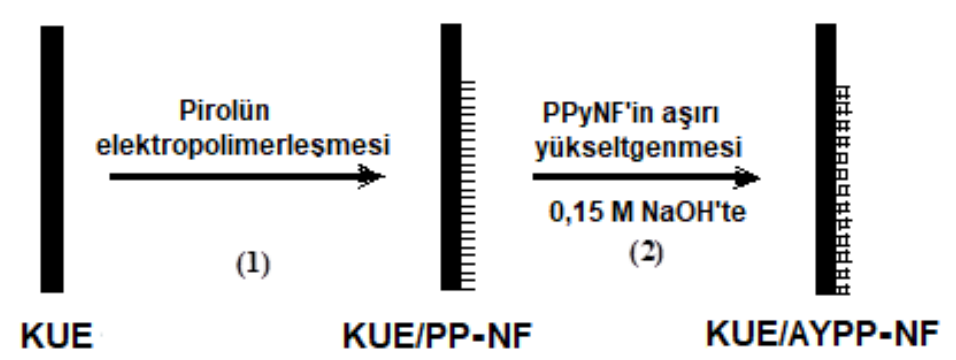

Şekil 3. KUE/AYPP-NF elektrotların hazırlanma şeması

Karşılaşıtırma çalışmalarında kullanmak için aynı işlem sırası takip edilerek $0,10 \mathrm{M} \mathrm{LiClO}_{4}$ ve $0,10 \mathrm{M}$ pirol $\left(\mathrm{Na}_{2} \mathrm{CO}_{3}\right.$ içermeyen) içeren çözeltiden nano fiber yapıda olmayan polipirol elektrotlar (KUE/AYPP) hazırlanmıştır.

\subsubsection{Elektroanalitik Ölçümler}

Dönüşümlü voltametri (DV) ve diferansiyel puls voltametri (DPV) ölçümleri üç elektrotlu hücrede gerçekleştirilmiştir. Çalışma elektrotlarının 0,80 cm'lik kısmı çözelti içine daldırılarak ölçümler gerçekleştirilmiş̧ir. Çözeltideki çözünmüş oksijen ölçümlerden önce uzaklaştırılmıştır. Diferansiyel puls voltamogramları CompactStat model (Ivium) potansiyostat-galvanostat cihazı kullanılarak elde 
edilmiş olup uygulanan parametreler şunlardır: puls süresi $50 \mathrm{~ms}$, puls genliği (amplitude) $50 \mathrm{mV}$, tarama hızı $20 \mathrm{mV} / \mathrm{s}$. Grafiklerde belirtilen her bir akım değeri 5 ölçümün ortalamasıdır. DPV ölçümlerinden elde edilen akımlar Ivium Soft yazılımında "baseline" düzeltmesi yapılarak elde edilmiş̧ir.

\section{Araştırma Sonuçları ve Tartışma}

\subsection{Polipirol Elektrotların Performansına Yüzey Morfolojisinin Etkisi}

Elektropolimerleşme ile sentezlenen polipirolün morfolojisi kullanılan karşıt iyona, çözücüye, polimerizasyon ortamı vb. parametrelere bağlıdır. Polipirol filmlerinin yüzey morfolojisi daha önceki çalışmalarımızda tespit edilmiş ve incelenmiştir (Özcan ve ark., 2008). Bu çalışmada karşılaştırma amacıyla KUE yüzeyinde elde edilen PP'nin morfolojisi karnabahar yapısına benzemektedir. Karnabahar yapısındaki PP destek elektrolit olarak sadece $\mathrm{LiClO}_{4}$ içeren sulu çözeltide hazırlanmıştır. Diğer yandan $\mathrm{LiClO}_{4}$ ile beraber $\mathrm{Na}_{2} \mathrm{CO}_{3}{ }^{\prime}$ nn da bulunduğunda sulu çözeltide elde edilen polipirol (PP-NF) 50 ile $80 \mathrm{~nm}$ arası çaplarına sahip nanofiber yapıdadır (Özcan ve ark., 2008). Bu yapı sayesinde etkin yüzey alanı artmaktadır.

Nanofiber yapının yüzey alanını artırması epinefrin tayininde de etkisini göstermektedir. Şekil 4'te, pH'sı 4 olan $0,10 \mathrm{M}$ derişimindeki fosfat tamponunda (FT) $200 \mu \mathrm{M}$ epinefrin varlı̆̆ında KUE, KUE/AYPP ve KUE/AYPP-NF ile elde edilen dönüşümlü voltamogramlar görülmektedir. Şekil 4 'teki voltamogramlardan görüldüğü gibi epinefrin yükseltgenmesine ait pik akımı değerleri KUE yüzeyine modifiye edilmiş aşırı yükseltgenmiş polipirol ile kayda değer bir şekilde artmaktadır. Ayrıca nanofiber yapının etkisiyle elde edilen akım değeri nanofiber olmayan yapıya göre daha da artmaktadır. Bu nedenle çalışmada, nanofiber yapılı olan aşırı yükseltgenmiş polipirol modifiye KUE elektrot tercih edilmiştir. Aynı zamanda yükseltgenmenin gerçekleştiği gerilim değerinin KUE’a göre 0,20 V daha düşük değerlere kayması elektrokatalitik bir etkinin göstergesidir. Li ve Lin (2007) aşırı yükseltgenmiş polipirolün epinefrin ve ürik asit gibi moleküllerin elektrokimyasal tayinine yönelik iyileştirici etkisini göstermiş ve yapının altın nanoyapılar ile birlikte kullanılmasıyla performansta bir miktar daha artma olduğunu göstermişlerdir. Ancak aşırı yükseltgenmiş polipirolün kendisinin nanofiber yapılı olarak eldesinin epinefrin tayinlerinde performansı daha da iyileştirdiğini gösteren bir çalışma şu ana kadar gerçekleştirilmemiştir.

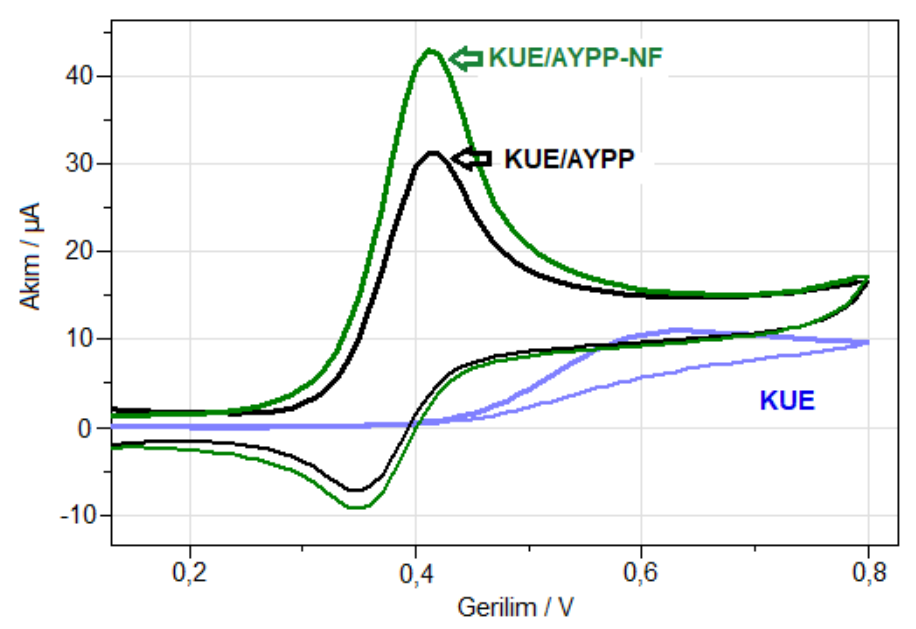

Şekil 4. KUE, KUE/AYPP ve KUE/AYPP-NF elektrotların $200 \mu$ M epinefrin içeren FT $(p H$ 4,0) içindeki dönüşümlü voltamogramları.

\subsection{Așırı Yükseltgenmenin Polipirol Modifiye Elektrotlara Etkisi}

Epinefrin tayinlerinde kullanılan PP aşırı yükseltgenme işlemine tabi tutulmaktadır. Çünkü elektroaktif özellikteki polipirol kendine ait geniş bir indirgenme ve yükseltgenme pikine sahiptir. Dolayısıyla aşırı yükseltgeme işlemine tabi tutulmazsa analit molekülünün sinyali ile girişim yapmakta veya analit sinyalini tamamen örtmektedir. Bu nedenle aşırı yükseltgenerek elektroaktifliklerinin mümkün olan en alt seviyeye düşürülmesi gerekir. $\mathrm{Bu}$ işlem yapıldığında elde edilen aşırı yükseltgenmiş PP elektrokimyasal sensör uygulamalarında düşük cevapların elde edilmesinde kullanılabilmektedir. Şekil 5'te KUE/PP-NF ve KUE/AYPP-NF elektrotların pH'sı 4,0 olan FT'de DPV ile elde edilen voltamogramları görülmektedir. KUE/PP-NF'in kendisine ait elektrokimyasal cevabı oldukça yüksek iken KUE/AYPP-NF kullanıldığında oldukça düşük seviyelere inmektedir. 


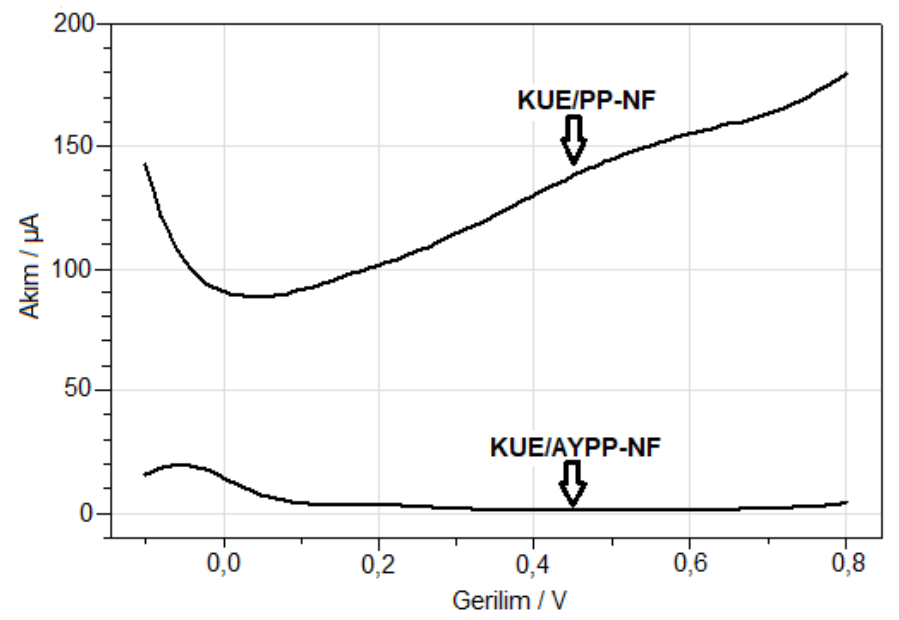

Şekil 5. KUE/PP-NF ve KUE/AYPP-NF elektrotların pH 4,0 olan FT çözeltisindeki DP voltamogramlart.

\section{3. Çözelti pH'sının Epinefrin Tayinlerine Etkisi}

KUE ve KUE/AYPP-NF elektrotlar epinefrin analizlerinde kullanılırken önemli parametrelerden biri ortam pH'ıdır. Bu nedenle öncelikle farklı pH değerlerindeki FT içinde $100 \mu \mathrm{M}$ epinefrin varlığında DPV tekniği ile epinifrine ait yükseltgenme pik akımı değerleri belirlenmiştir. Şekil 6'da pH değişimi ile akım arasındaki ilişki görülmektedir. KUE/AYPP-NF kullanıldığında en yüksek pik akımına pH 4,0 değerindeki FT çözeltisinde ulaşılmıştır. Bununla beraber KUE ile ise pH 8,0 değeri en yüksek pik akımının elde edildiği değerdir. KUE yüzeyindeki AYPP yapının epinefrin ile etkileşimi değiştirdiği ve elektrokimyasal performansı artırdığı bu verilerden anlaşılmaktadır. Polipirolün aşırı yükseltgenmesi ile polimer zincirindeki katyonik yükler azaldığından yapı katyonik türlere karşı seçici hale gelmektedir (Ersöz ve ark., 2002). Epinefrinin pKa değeri 8,88 olup, asidik ortamda protonlanarak pozitif yüklü hale gelmekte (Li ve Lin, 2007) ve protonlanmasının artmasıyla iki yapı arasındaki etkileşim de artmaktadır. Deneysel sonuçlar bu etkileşimin $\mathrm{pH} 4,0$ değerinde en yüksek olduğunu göstermektedir. Koyun ve ark. (2017) epinefrinin pKa değere çok yakın olan dopaminin (pKa 8,71) aşırı yükseltgenmiş nanoyapılı polipirol ile tayininde en yüksek akım değerine pH 4,0'te ulaşmışlardır. Buna benzer bir etkileşim KUE'ta olmadığından, KUE kullanıldığında epinefrin için en yüksek akım farklı bir pH değerinde (pH 8) elde edilmiştir. Ayrıca pH 4,0 değeri için KUE/AYPP-NF ile elde edilen yükseltgenme pik akımı değeri KUE ile elde edilenden yaklaşık 10 kat fazladır. Bu nedenle kalibrasyon doğrusu çalışmaları pH 4,0 FT içinde gerçekleştirilmiştir.

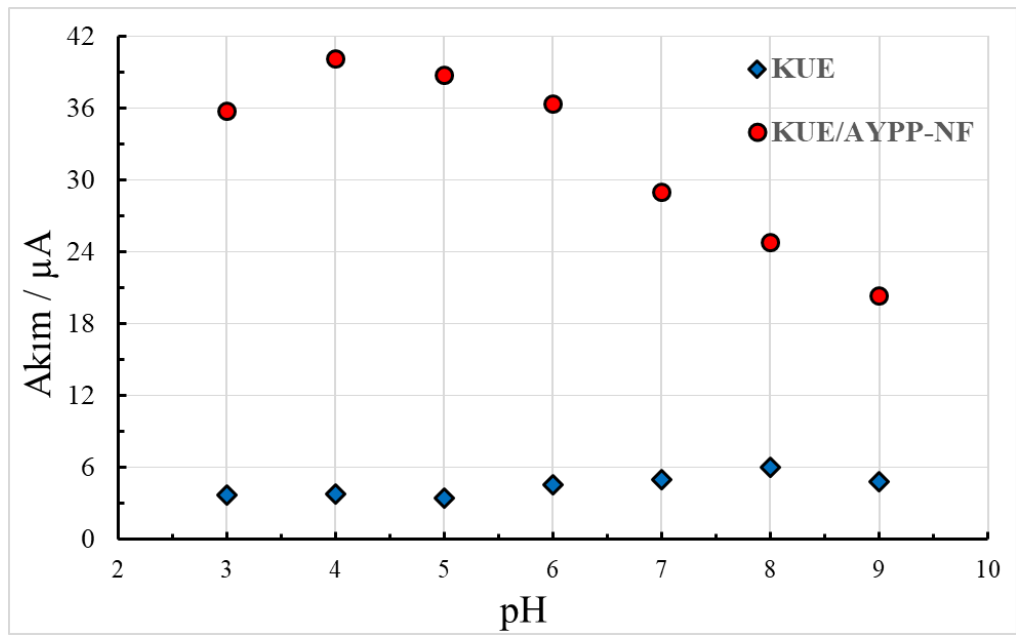

Şekil 6. Farklı pH'lardaki FT içinde 100 MM epinefrin için DPV ile elde edilen yükseltgenme pik akımları.

\subsection{Epinefrin Derişimi ve Yükseltgenme Akımı Arasındaki İlişki}

KUE/AYPP-NF elektrotlar kullanılarak epinefrin derişimi ile epinefrin yükseltgenme pik akımın değişimi diferansiyel puls voltametri (DPV) tekniği ile çalışılmıştır. Şekil 7'de KUE/AYPP-NF elektrotlar ile farklı derişimlerde epinefrin içeren FT (pH 4,0) içinde elde edilen pik akımı değerlerinin grafiği görülmektedir. Şekil 7’den görüldüğü gibi pik akımı ile epinefrin derişimi arasında 10 $\mu \mathrm{M}$ ile $200 \mu \mathrm{M}$ aralığında 0,998 korelasyon katsayısı ile doğrusallık vardır. Aynı zamanda KUE ile kıyaslandığında yapılan modifikasyonun hassasiyette önemli derecede arttış sağladığı da görülmektedir. Tayin sınırı (LOD) 2,2 $\mu \mathrm{M}$ olarak hesaplanmıştır $(\mathrm{S} / \mathrm{N}=3)$. Şekil 8'de ise KUE/AYPP-NF elektrotlar kullanılarak epinefrin için doğrusal cevabın elde edildiği $10 \mu \mathrm{M}$ ile $200 \mu \mathrm{M}$ aralığında elde edilen diferansiyel puls voltamogramları görülmektedir. 


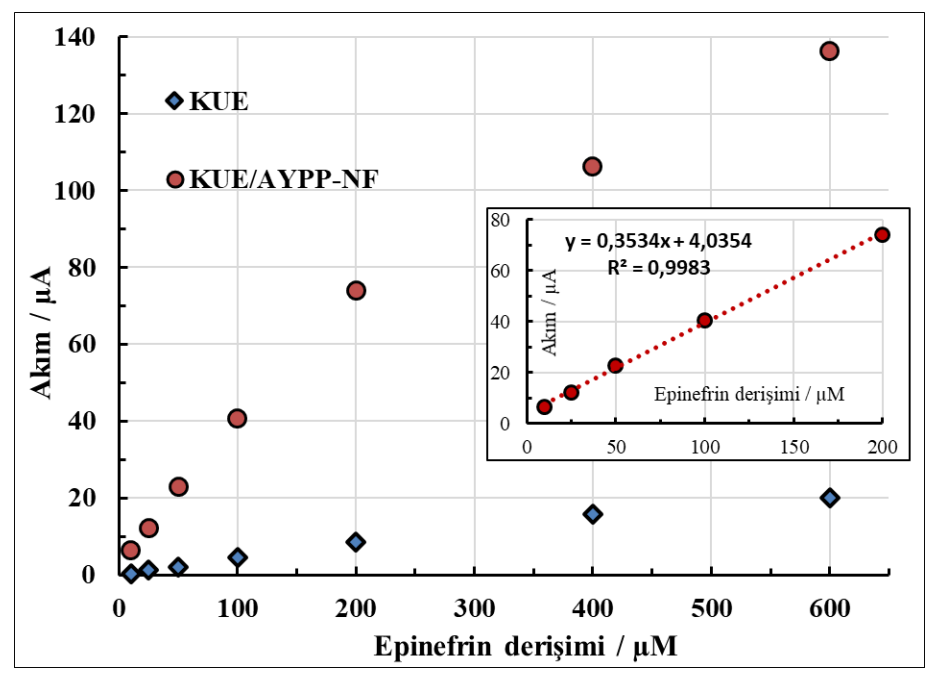

Şekil 7. KUE ve KUE/AYPP-NF kullanılarak FT içinde (pH 4,0) DPV ile farklı derişimlerdeki epinefrine ait yükseltgenme akımları.

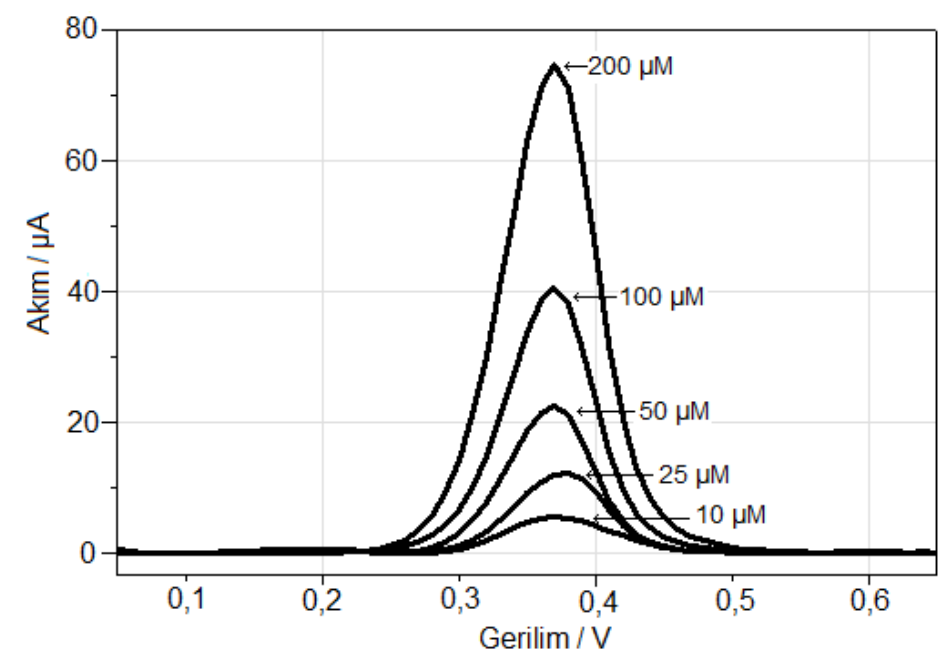

Şekil 8. KUE/AYPP-NF ile pH 4,0 FT çözeltisinde farklı derişsimlerdeki epinefrin için elde edilen DP voltamogramları.

\section{Sonuçlar ve Öneriler}

Bu çalışmada, elektrokimyasal olarak nanofiber yapılı polipirol sentezlenerek sonrasında aşırı yükseltgenmiş ve epinefrin (adrenalin) tayinlerinde kullanılabilirliği incelenmiştir. Bu çalışmaların tamamında çalışma elektrodu olarak ucuz, kolay bulunabilen ve elektropolimerizasyona uygun olan kalem ucu elektrot (KUE) kullanılmıştır. Epinefrinin elektrokimyasal tayinlerine yönelik çalışmalar DV ve DPV teknikleri kullanılarak fosfat tampon içerisinde gerçekleştirilmiştir. Değerlendirmelerde epinefrinin yükseltgenme pik akımı değeri dikkate alınmıştır.

Epinefrin tayinlerinde elektrokimyasal olarak KUE yüzeyinde sentezlenen aşırı yükseltgenmiş nanofiber yapılı polipirol (KUE/AYPP-NF) kullanılmıștır. Nanofiber yapıda olmayan aşırı yükseltgenmiş polipirol elektrottan daha yüksek performansa sahip olduğu gösterilmiştir. KUE/AYPP-NF kullanılarak epinefrin tayinlerine pH'nın etkisi DPV tekniği ile incelenmiş ve KUE/AYPP-NF için en yüksek yükseltgenme akımına pH 4,0 değerinde ulaşılmışıı. DPV tekniği kullanılarak KUE/AYPP-NF ile $10 \mu \mathrm{M}$ ile $200 \mu \mathrm{M}$ aralığında epinefrin yükseltgenme akımına karşı doğrusal bir cevap elde edilmiştir. Tayin sınırı (LOD) ise 2,2 $\mu \mathrm{M}$ olarak bulunmuştur $(\mathrm{S} / \mathrm{N}=3)$. KUE/AYPP-NF elektrot ile elde edilen analitik sonuçların nanoyapılar veya nanoparçacıklar ile modifiye edilmiş elektrotlar ile karşılaş̧ırması Tablo 1'de verilmiştir. Tablo 1 incelendiğinde, bu çalışmada kullanılan modifiye elektrodun performansının çoğu karbon kökenli nanoyapılarla modifiye edilmiş elektrotlarınkiler ile yarışabilecek düzeyde olduğu görülmektedir.

Elde edilen sonuçlar, KUE yüzeyinde elektrokimyasal olarak sentezlenen aşırı yükseltgenmiş nanofiber yapılı polipirolün epinefrin tayinlerinde etkili ve hassas bir elektrokimyasal sensör olarak kullanılabileceğini göstermektedir. Kullanılan yöntem basit ve malzemelerin maliyeti düşüktür. $\mathrm{Bu}$ yönüyle ticari açıdan önemli bir etken olan düşük maliyetli tayinlerin yapılmasını mümkün kılmaktadır.

Ayrıca yapılan modifikasyonların küçük boyutlara indirgenmiş analiz sistemlerinde uygulanması mümkündür. Bunun haricinde yüksek performanslı sıvı kromatografi veya akış enjeksiyon analiz sistemlerinde kullanılan elektrokimyasal dedektörlerin hassasiyetini artırmak amaciyla da kullanılabilir. 
Tablo 1. KUE/AYPP-NF elektrodunun epinefrin tayinindeki analitik performansının karşılaştırılması

\begin{tabular}{|l|c|c|c|}
\hline \multicolumn{1}{|c|}{ Elektrot } & Doğrusal aralık $(\boldsymbol{\mu M})$ & Tayin sınırı (LOD) $(\boldsymbol{\mu M})$ & Kaynak \\
\hline $\mathrm{CPE} / \mathrm{ZnFe} \mathrm{O}_{4} \mathrm{NPs}$ & $5-100$ & 0,7 & (Tavakkoli ve ark. 2018) \\
\hline $\mathrm{CPE} / \mathrm{DH}-\mathrm{CN}$ & $5-20$ & 1,0 & (Mazloum-Ardakani ve ark. 2012) \\
\hline $\mathrm{SPE} / \mathrm{Cu}$ & $10-600$ & 2,5 & Soofiabadi ve ark. 2017) \\
\hline $\mathrm{SSE} / \mathrm{SWCNT}$ & $2-100$ & 2,0 & (Valentini ve ark. 2007) \\
\hline PSRA/MCNTPE & $2,0-64$ & 1,0 & (Manjunatha ve ark. 2018) \\
\hline KUE/AYPP-NF & $10-200$ & 2,2 & Bu çalışma \\
\hline
\end{tabular}

$\mathrm{CPE} / \mathrm{ZnFe}_{2} \mathrm{O}_{4} \mathrm{NPs}$ : Çinko ferrit nanoparçacıklarla modifiye karbon pasta elektrot

CPE/DH-CN: Karbon nanoparçacık ve hidrokinon türevi modifiye karbon pasta elektrot

$\mathrm{SPE} / \mathrm{Cu}: \mathrm{Cu}(\mathrm{II})$ nanokompleks modifiye grafit screen printed elektrot

SSE/SWCNT: Tek duvarlı karbon nanotüp modifiye paslanmaz çelik elektrot

PSRA/MCNTPE: Aşırı yükseltgenmiş poli(Solid Red A) filmi modifiye karbon nanotüp pasta elektrot

KUE/AYPP-NF: Aşırı yükseltgenmiş nanofiber yapılı polipirol modifiye kalem ucu elektrot

\section{Teşekkür}

Bu çalışmanın gerçekleşmesi için verdiği mali destekten dolayı (Proje No: 10.FENED.15) Afyon Kocatepe Üniversitesi Bilimsel Araştırmalar Koordinasyon birimine teşekkür ederim.

\section{Kaynaklar}

Adhikari, B. \& Majumdar, S. (2004). Polymer in sensor applications. Progress in Polymer Science, 29, 699-766.

Ahuja, T., Mir, I.A., Kumar, D. \& Rajesh (2007). Biomolecular immobilization on conducting polymers for biosensing applications. Biomaterials, 28, 791-805.

Ayazi, Z., Izadyar, S. \& Habibi, B. (2018). Ionic liquid/single-walled carbon nanotubes composite film modified carbon-ceramic electrode as an electrochemical sensor for the simultaneous determination of epinephrine and uric acid. Journal of the Chinese Chemical Society, 65(12), 1510-1520.

Babu, K.J., Sheet, S., Lee, Y.S. \& Kumar, G.G. (2018). Three-Dimensional Dendrite Cu-Co/Reduced Graphene Oxide Architectures on a Disposable Pencil Graphite Electrode as an Electrochemical Sensor for Nonenzymatic Glucose Detection. ACS Sustainable Chemistry \& Engineering, 6(2), 1909-1918.

Bergmann, E.D. \& Goldschmidt, Z. (1968). Some epinephrine analogs. Journal of Medicinal Chemistry 11, 1121-1125.

Canevari, T.C., Thiago, C., Nakamura, M., Cincotto, F.H., de Melo, F.M. \& Toma, H.E. (2016). High performance electrochemical sensors for dopamine and epinephrine using nanocrystalline carbon quantum dots obtained under controlled chronoamperometric conditions. Electrochimica Acta, 209, 464-470.

Devkota, L., Nguyen, L.T., Vu, T.T., \& Piro, B. (2018). Electrochemical determination of tetracycline using AuNP-coated molecularly imprinted overoxidized polypyrrole sensing interface. Electrochimica Acta, 270, 535-542.

Dong, W.H., Ren, Y.P., Bai, Z.X., Jiao, J., Chen, Y., Han, B.K. \& Chen, Q. (2018). Synthesis of tetrahexahedral Au-Pd core-shell nanocrystals and reduction of graphene oxide for the electrochemical detection of epinephrine. Journal of Colloid and Interface Science, 512, 812-818.

Ersöz, A., Gavalas, V.G. \& Bachas, L.G. (2002). Potentiometric behavior of electrodes based on overoxidized polypyrrole films. Analytical and Bioanalytical Chemistry, 372, 7-8.

Fernandez, I., Trueba, M., Nunez, C.A. \& Rieumont, J. (2005). Some features of the overoxidation of polypyrrole synthesized on austenitic stainless steel electrodes in aqueous nitrate solutions. Surface and Coatings Technology, 191, 134-139.

Gao, W., Song, J. \& Wu, N. (2005). Voltammetric behavior and square-wave voltammetric determination of trepibutone at a pencil graphite electrode. Journal of Electroanalytical Chemistry, 576, 1-7.

Gu, J.W. Dai, H.X., Kong, Y., Tao, Y.X., Chu, H.X. \& Tong, Z.F. (2016). Chiral electrochemical recognition of cysteine enantiomers with molecularly imprinted overoxidized polypyrrole-Au nanoparticles. Synthetic Metals, 222, 137-143. Part: A Special Issue.

Guerrieri, A., De Benedetto, G.E., Palmisano, F. \& Zambonin, P.G. (1998). Electrosynthesized non-conducting polymers as permselective membranes in amperometric enzyme electrodes a glucose biosensor based on a co-crosslinked glucose oxidize/overoxidized polypyrrole bilayer. Biosensors and Bioelectronics, 13, 103-112.

Hsu, C.W. \& Yang, M.C. (2008). Electrochemical epinephrine sensor using artificial receptor synthesized by sol-gel process. Sensors and. Actuators B, 134, 680-686.

Kalimuthu, P. \& Abraham, S. (2009). Simultaneous determination of epinephrine, uric acid and xanthine in the presence of ascorbic acid using an ultrathin polymer film of 5-amino-1,3,4-thiadiazole-2-thiol modified electrode. Analytica Chimica Acta, 647, 97-103.

Komaba, S., Seyama, M., Momma, T. \& Osaka, T. (1997). Potentiometric biosensor for urea based on electropolymerized electroinactive polypyrrole. Electrochimica Acta, 42, 383-388.

Koyun, O., Gursu, H. Gorduk, S. \& Sahin, Y. (2017). Highly Sensitive Electrochemical Determination of Dopamine with an Overoxidized Polypyrrole Nanofiber Pencil Graphite Electrode. International Journal of Electrochemical Science, 12(7), 64286444.

Lawson, A.G. \& Gorman, R.I. (2008). Research Progress on Epinephrine, Nova Science Pub. Inc. 
Lavanya, N., Fazio, E., Neri, F., Bonavita, A., Leonardi, S.G., Neri, G. \& Sekar, C. (2015). Simultaneous electrochemical determination of epinephrine and uric acid in the presence of ascorbic acid using $\mathrm{SnO} 2 /$ graphene nanocomposite modified glassy carbon electrode. Sensors and Actuators B-Chemical, 221, 1412-1422.

Li, J. \& Lin, X.-Q. (2007). Electrodeposition of gold nanocluster on overoxidized polypyrrole film modified glassy carbon electrode and its application fort he simultaneous determination of epinephrine and uric acidunder coexistence of ascorbic acid. Analytica Chimica Acta, 596, 222-230.

Majidi, M.R., Jouyban A. \& Asadpour-Zeynali K. (2006). Voltammetric behaviour and determination of ionized in pharmaceuticals by using overoxidized polypyrrole glassy carbon modified electrode. Journal of Electroanalytical Chemistry, 589, 32-37.

Manjunathaa, J.G., Deramana, M., Basria, N.H. \& Taliba, I.A. (2018). Fabrication of poly (Solid Red A) modified carbonnano tube paste electrode and its application forsimultaneous determination of epinephrine, uricacid and ascorbic acid. Arabian Journal of Chemistry, 11, 149-158.

Mazloum-Ardakani, M., Rajabzadeh, N., Dehghani-Firouzabadi, A., Sheikh-Mohseni, M.A., Benvidi, A., Naeimi, H., Akbari, M. \& Karshenas, A. (2012). Carbon nanoparticles and a new derivative of hydroquinone for modification of carbon paste electrode for simultaneous determination of epinephrine and acetaminophen. Analytical Methods, 4, 2127-2133.

Mostany, J. \& Scharifker, B.R. (1996). Impedance spectroscopy of undoped, doped and overoxidized poypyrrole films. Synthetic Metals, 87, 179-185.

Özcan, L., Şahin, Y. ve Türk, H. (2008). Non-enzymatic glucose biosensor based on overoxidized polypyrrole nanofiber electrode modified with cobalt(II) phthalocyanine tetrasulfonate. Biosensors and Bioelectronics, 24, 512-517.

Özcan, A., İlkbas, S. \& Özcan, A.A. (2017). Development of a disposable and low-cost electrochemical sensor for dopamine detection based on poly(pyrrole-3-carboxylic acid)-modified electrochemically over-oxidized pencil graphite electrode. Talanta, 165, 489495.

Özkorucuklu, S. P., Özcan, L., Yucel Sahin, Y. \& Alsancak, G. (2011). Electroanalytical determination of some sulfonamides on overoxidized polypyrrole electrodes. Australian Journal of Chemistry, 64, 965-972.

Ramanavičius, A., Ramanavičiene, A. \& Malinauskas, A. (2006). Electrochemical sensors based on conducting polymer-polypyrrole. Electrochimica Acta, 51, 6025-6037.

Rezaei, B., Boroujeni, M.K.L. \& Ensafi, A.A. (2014). Caffeine electrochemical sensor using imprinted film as recognition element based on polypyrrole, sol-gel, and gold nanoparticles hybrid nanocomposite modified pencil graphite electrode. Biosensors and Bioelectronics, 60, 77-83.

Retama, J.R., Mecerreyes, D., Lopez-Ruiz, B. \& Cabarcos, E.L. (2005). Synthesis and characterization of semiconducting polypyrrolepolyacrylamide microparticles with GOx for biosensor applications. Colloids and Surfaces A, 270-271, $239-244$.

Silva, L.I.B., Ferreira, F.D.P., Freitas, A.C., Rocha-Santos, T.A.P. \& Duarteb, A.C. (2009). Optical fiber biosensor coupled to chromatographic separation for screening of dopamine, norepinephrine and epinephrine in human urine and plasma. Talanta, 80, 853-857.

Şahin, Y., Ercan, B. \& Şahin, M. (2008). In situ electrochemical solid-phase extraction of anions and cations using polypyrrole and overoxidized sulfonated polypyrrole. Talanta, 75, 369-375.

Selbst, S.M. \& Cronan K., (2000). Pediatric Emergency Medicine Secrets, Elsevier Health Sciences.

Soofiabadi, F., Amiri, A. \& Jahani, S. (2017). Application of Cu(II) nanocomplex modified graphite screen printed electrode to improve the sensitivity and selectivity for epinephrine detection. Analytical and Bioanalytical Electrochemistry, 9(3), 340-350.

Tavakkoli, N., Soltani, N., Shahdost-fard, F., Ramezani, M., Salavati, H. \& Jalali, M.R. (2018). Simultaneous voltammetric sensing of acetaminophen, epinephrine and melatonin using a carbon paste electrode modified with zinc ferrite nanoparticles, Microchimica Acta, 185, 479(11 sayfa).

Tian, Y., Wang, J., Wang, Z. \& Wang, S. (2004). Electroreduction of nitrite at an electrode modified with polypyrrole nanowires. Synthetic Metals, 143, 309-313.

Valentini, F., Palleschi, G., Lopez Morales, E., Orlanducci, S., Tamburri, E. \& Terranova, M.L. (2007). Functionalized single-walled carbon nanotubes modified microsensors for the selective response of epinephrine in the presence of ascorbic acid. Electroanalysis 19, 859-869.

Vestergaard, M., Kerman, K. \& Tamiya, E. (2005).An electrochemical approach for detecting copper-chelating properties of flavonoids using disposable pencil graphite electrodes: Possible implications in copper-mediated illnesses. Analytica Chimica Acta, 538, 273281.

Wang, J., Kawde A.-N. \& Sahlin, E. (2000). Renewable pencil electrodes for highly sensitive stripping potentiometric measurements of DNA and RNA. Analyst, 125, 5-7.

Wang, L.X., Li, X.G. \& Yang, Y.L. (2001). Preparation, properties and applications of polypyrroles. Reactive and Functional Polymers, 47, 125-139.

Wu, S.X., Zeng, J.M., Xie, H. \& Ng, S.H. (2016). Capsaicin determination and chili sauce discrimination using low-cost and portable electrochemical sensors based on all graphite pencil electrodes. Analytical Methods, 8(39), 7025-7029. 